ИЗВЕСТИЯ АКАДЕМИИ НАУК ЭСТОНСКОП ССР. ТОМ 30 ХимИЯ. 1981, № 3

Н. ГНУСИН, Н. БЕРЕЗННА, РУтT ТОМСОН, Г. СТЕПАНОВА, Наталья КОНОНЕНКО

\title{
ЭЛЕКТРОХИМИЧЕСКОЕ ПОВЕДЕНИЕ АНИОНИТОВЫХ МЕМБРАН В РАСТВОРАХ ПОВЕРХНОСТНО-АКТИВНЫХ ОРГАНИЧЕСКИХ ВЕЩЕСТВ
}

\author{
(Представил О. Эйзен)
}

Возрастающее применение поверхностно-активных веществ (ПАВ) в промышленности и народном хозяйстве приводит к увеличению содержания их как в промышленных растворах, так и в природных водах. Поэтому при использовании методов электромембранной технологии для очистки и разделения растворов различного состава приходится учитывать изменения в ходе процесса, которые являются результатом взаимодействия ионообменных мембран с ионами или молекулами ПАВ. Сорбция ПАВ разных типов на ионитах в статических условиях изучена довольно детально $\left[{ }^{1,2}\right]$, но влияние ПАВ на поведение ионитовых мембран при прохождении через них электрического тока начинает привлекать внимание исследователей лишь в последнее время. Так, в работе $\left.{ }^{[3}\right]$ рассмотрено влияние алкилсульфонатов на процесс электродиализа. Целый ряд работ, посвященных эффектам отравления мембран различными ПАВ, выполнен Т. Сата и сотрудниками на образцах ионитов и ПАВ, выпускаемых японскими фирмами [4,5].

В данной работе предпринята попытка рассмотреть взаимодействие типичных ПАВ анионного типа с анионитовыми мембранами. Поскольку в настоящее время ведутся поиски новых решений в создании анионитов со структурой, устойчивой к отравлению крупными органическими ионами, представляет интерес исследовать электрохимическое поведение мембран с разной пористостью. В качестве объектов исследования были использованы мембраны типа МА-41, МА-41И, МА-41П на основе анионообменных смол АВ-17, АВ-17И, АВ-17П соответственно. Эти мембраны имеют одинаковую химическую природу полимерной матрицы: полистирольные цепи, сшитые дивинилбензолом, с группами $-\mathrm{N}\left(\mathrm{CH}_{3}\right)_{3}^{+}$в качестве фиксированных ионов. Мембраны различаются своей физической пористостью: обычная промышленная мембрана МA-41 относится к гетеропористым, а мембраны МА-41И и МА-41П - к изопористым и макропористым ионитам. Макропористые мембраны содержат в своей структуре реальные физические поры размером до нескольких десятков микрон. Средний диаметр пор промышленной мембраны МА-41 имеет порядок от единицы до $10^{2} \AA$. Мембраны изопористой структуры отличаются наиболее равномерным распределением сшивки в ионите, а по своей пористости занимают промежуточное положение между гетеропористыми и макропористыми [ $\left.{ }^{6}\right]$. 
Исследовалось взаимодействие перечисленных мембран с типичными ПАВ анионного типа:

децилсульфат натрия

додецилсульфат натрия

натриевая соль додецилового эфира сульфоуксусной кислоты<smiles>CCCCCCCOS(=O)(=O)O[Na]</smiles><smiles>CCCCOC(=O)CS(=O)(=O)[O-]</smiles><smiles>O=S(=O)(O)c1ccccc1</smiles>

Сульфоэфиры алкиловых спиртов синтезировались путем обработки в растворе дихлорэтана индивидуальных алифатических спиртов комплексом серного ангидрида с пиридином или диоксаном с последующим выделением активного вещества из раствора органического растворителя и перекристаллизацией из этилового спирта. Натриевая соль додецилового эфира сульфоуксусной кислоты была получена путем каталитического присоединения соответствующего алкена к хлоруксусной кислоте, выделением и очисткой хлорэфиров с последующим сульфонированием хлорэфира сульфитом натрия, выделением активного вещества и перекристаллизацией из ацетона. нат натрия был синтезирован из $н$-каприловой кислоты с получением хлорангидрида и последующим ацилированием хлорангидридом бензола, гидрированием образовавшихся кетонов и сульфированием фенилалканов в ядро. Конечный продукт перекристаллизовывался из пиридина. Все приведенные в работе вещества идентифицированы методами ИК- и 'ЯМР-спектроскопии и элементарным анализом.

В связи с тем, что эффективность электродиализных методов определяется в первую очередь транспортными свойствами ионитовых мембран, в работе были исследованы удельная электропроводность $(\varkappa)$ и коэффициенты проницаемости $(P)$ указанных образцов в зависимости от концентрации водных растворов ПАВ в статических условиях эксперимента. Мембраны перед измерениями были химически кондиционированы (по общепринятой методике) переведением в $\mathrm{OH}^{-}$-форму [7], после чего выдержаны в течение 48 ч в 2 н. растворе $\mathrm{Na}_{2} \mathrm{SO}_{4}$. Таким образом, исходной формой мембран служила сульфатная для того, чтобы исключить возможное влияние изменения $\mathrm{pH}$ системы. Характеристики мембран изучались после выдерживания их в сменяемых водных растворах указанных веществ до постоянного зиачения электропроводности раствора над мембраной. Величина $x$ измерялась ртутно-контактным методом, согласно работе [ $\left.{ }^{8}\right]$, с точностью $\pm 3 \%$. $P$ образцов был определен в интегральном виде для переноса раствора $\mathrm{Na}_{2} \mathrm{SO}_{4}(0,1$ н.) с точностью 3-5\%. Мембрана служила перегородкой в ячейке, состоящей из двух камер, одна из которых (I) заполнялась раствором $\mathrm{Na}_{2} \mathrm{SO}_{4}$, а другая (II) - дистил- 


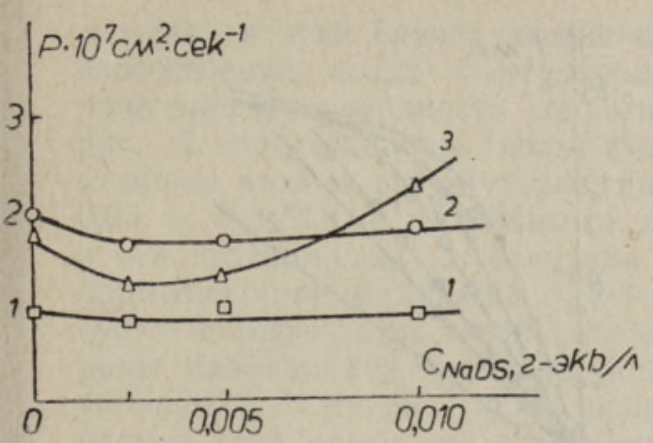

Рис. 1. Зависимость проницаемости анионитовых мембран от концентрации равновесного раствора децилсульфата натрия: 1 - МА-41; $2-$ МА-41К; 3 МА- 41 I.

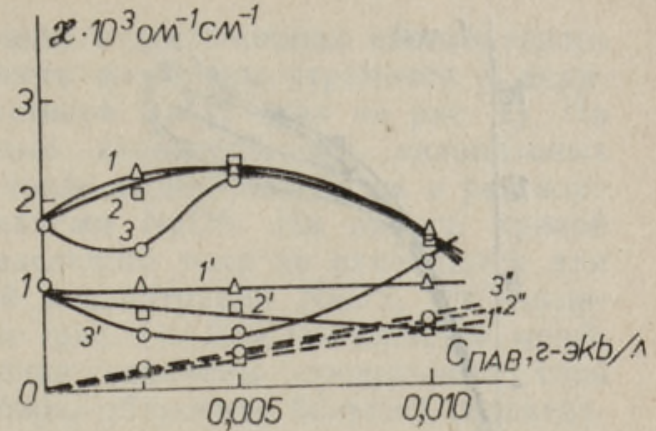

Рис. 2. Влияние природы и концентрации ПАВ на электропроводность мембран: $1-3-\mathrm{MA}-41 ; 1^{\prime}-3^{\prime}-\mathrm{MA}-41 \Pi$; $1^{\prime \prime}-3^{\prime \prime}$ - растворы ПАВ; $1, I^{\prime}$ и $I^{\prime \prime}-$ натриевая соль додецилового эфира сульфоуксусной кислоты; $2,2^{\prime}$ и $2^{\prime \prime}-$ н-1-октилбензолсульфонат натрия; $3,3^{\prime}$ и $3^{\prime \prime}-\mathrm{NaDS}$.

лированной водой $\left(x=1-1,2 \cdot 10^{-6} o_{M^{-1}} c M^{-1}\right)$. Камера II снабжена парой платинированных платиновых электродов для кондуктометрической регистрации нарастания в ней концентрации электролита в результате диффузии. Эксперимент проводился в квазистационарном режиме. Для расчета интегрального коэффициента проницаемости использовалось уравнение, содержащее экспериментально определяемые параметры:

$$
P=\frac{\sigma V}{S \Delta C^{\prime}} \omega
$$

где $S$ и $\sigma$ - площадь и толщина мембраны; $V$ - объем камеры; $\Delta C^{\prime}$ - разность концентраций по обе стороны мембраны в начальный момент времени; $\omega=\frac{\Delta C^{\prime \prime}}{\Delta \tau}-$ скорость нарастания концентрации электролита в камере II, определяемая по тангенсу угла наклона кинетической зависимости изменения проводимости растворов в этой камере.

Полученные характеристики мембран, выдержанных в растворах ПАВ, сопоставлялись с аналогичными величинами для исходной формы мембран. Последние отмечены на оси ординат (рис. $1 ; 2)$. На рис. 1 приведены значения $P$ для трех типов мембран в зависимости от концентрации раствора децилсульфата натрия (NaDS), из которых видно, что для мембран MA-41 и MA-41И влияние DS-иона не очень заметно, а для пористой мембраны МА-41П зависимость имеет вид кривой, вогнутой к оси концентрации. На рис. 2 представлены результаты определения $x$ мембран MA-41 и МА-41П в зависимости от концентрации поверхностно-активных органических анионов (ПАОА) и их природы. Концентрационные зависимости мембран имеют более сложный ход по сравнению с характерной формой кривых $x-C$ в минеральных растворах $\left[{ }^{9}\right]$. На рис. 2 приведены также зависимости $x$ водных растворов исследованных ПАВ в том же диапазоне концентраций. Изломов в области критической концентрации мицеллообразования не наблюдалось, хотя, по литературным данным, эта область начинается для исследованных веществ уже в миллинормальных растворах $\left[{ }^{10}\right]$. 


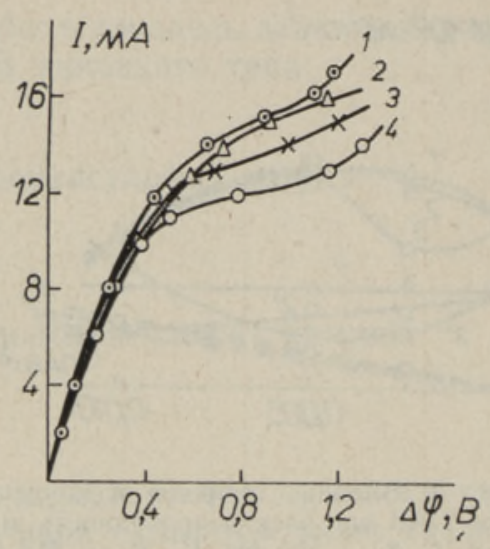

Рис. 3. Поляризационные кривые мембраны МА-4IИ, выдержанной в растворах: $1-0.05 \mathrm{H}$. $\mathrm{Na}_{2} \mathrm{SO}_{4}$ и 0,05 н. $\mathrm{Na}_{2} \mathrm{SO}_{4}+$ $+5 \cdot 10^{-4}$ моль/л ПАВ; 2 - до. децилсульфат натрия; $3-\mathrm{NaDS}$; 4 - натриевая соль додецилового эфира сульфоуксусной кислоты.

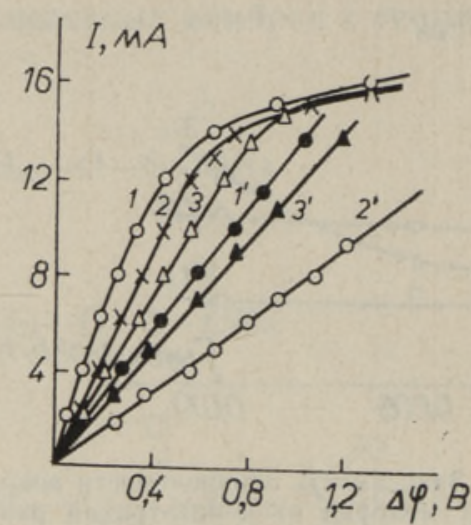

Рис. 4. Поляризационные кривые анионитовых мембран, выдержанных в растворе: $1-3-$ 0.05 н. $\quad \mathrm{Na}_{2} \mathrm{SO}_{4}+5 \cdot 10^{-4}$ моль/ $/$ $\mathrm{NaDS}$ и $1^{\prime}-3^{\prime}-0.05$ н. $\mathrm{Na}_{2} \mathrm{SO}_{4}+$ $+5 \cdot 10^{-3}$ моль/ $/ \mathrm{NaDS}: 1,1^{\prime}-$ МА- 41 И; 2, 2' - МА- $41 \Pi ; 3,3^{\prime}-$ MA-41.

В области истинных растворов исследованных анионов для мембран проявляется ситовой эффект, так что с ростом молекулярного веса поглощаемого иона возрастает степень уменьшения $\chi$. Для мембран, приведенных в равновесие с растворами 0,01 н. ПАВ, наблюдается заметное падение $x$ до значений, близких к этой характеристике в водных растворах соответствующих ПАВ.

Для изучения поведения мембран после контакта с растворами ПАВ при наложении внешнего электрического поля были измерены поляризационные кривые ионитовых мембран указанных структурных типов. Из литературных данных известно, что процесс электромембранной обработки растворов тем более эффективен, чем выше предельный ток и больше участок на поляризационной кривой, отвечающий так называемому допредельному состоянию мембраны. Измерения поляризационных характеристик были проведены с помощью обычной ячейки, типа описанной в работе [1']. Соответствующее значение мембранной разности потенциалов измерялось с помощью двух симметричных зондов, связанных с хлорсеребрянными электродами, используемыми для сравнения. Мембраны перед измерениями были выдержаны в растворе 0,05 н. сульфата натрия с различной добавкой ПАОА разной природы. Было установлено, что в пределах ошибки эксперимента в докритической области концентраций $5 \cdot 10^{-4}$ моль/л этих веществ ПАОА не оказывают заметного влияния на поляризационную кривую катионитовой мембраны МК-40. Для анионитовых мембран структуры того же типа наблюдается заметное сниженне предельного тока в растворе с добавкой ПАОА, возрастающее с увеличением молекулярного веса аниона (рис. 3). Увеличение концентрации органической добавки в растворе на порядок, соответствующее области начала мицеллообразования, приводит практически к вырождению поляризационных кривых всех мембран в омические прямые (рис. 4), как отмечалось и в работах $[3,4]$. По-видимому, электрохимическое состояние 
мембран в этом случае можно сравнить с достижением своеобразного изосостояния, когда электропроводность мембраны стремится к величине электропроводности водного раствора $\mathrm{NaDS}$ (как на рис. 2). На рис. 4 представлены вольт-амперные характеристики анионитовых мембран разных структурных типов после выдерживания их в растворе 0,05 н. $\mathrm{Na}_{2} \mathrm{SO}_{4}$ с различными добавками $\mathrm{NaDS}$. Ни наклон кривой к оси потенциалов, ни величина предельного тока не изменяются для промышленной мембраны при малой концентрации $\mathrm{NaDS}$, что согласуется с эффектами в проницаемости (рис. 1). Для изопористой мембраны наблюдается заметное понижение величины предельного тока (кривые $1,1^{\prime}$ на рис. 4), которое можно объяснить бо́льшей селективностью этой мембраны к органическому аниону по сравнению с поведением мембраны МА-41.

Таким образом, исследования электрохимических свойств анионообменных мембран разной структуры после контакта с водными растворами ПАВ, показали, что наблюдается сложная концентрационная зависимость, особенно для электропроводности мембран всех структурных типов, которая может быть интерпретирована с точки зрения состояния коллоидных систем, находящихся в фазе заряженной полимерной матрицы. Усложнение строения ПАОА вызывает увеличение селективности мембран к данному иону, что проявляется в более значительном уменьшении $\chi$ и предельного тока на поляризационных кривых.

\section{ЛИТЕРАТ УРА}

1. Самсонов Г. В., Т ростянская Е. Б., Елькин Г. Э. Ионный обмен. Л. 1969.

2. Шам анаев Ш. Ш., Пушкарев В. В., Пустовалов Н. Н. Сорбция поверхностно-активных веществ ионитом. - ЖФХ, 1973, т. 47, № 8, с. 20492051; № 9, c. $2340-2343$.

3. Золотарева Р. И., Котов В. В., Жарких В. Т., Кукуева В. В. Влияние алкилсульфонатов на электрохимические свойства ионитовых мембран. Электрохимия, 1977 , т. 13, № 9, с. $1412-1414$.

4. Sata, T., Izuo, R., Mizutani, Y., Y a mane, R. Transport properties of ion exchange membranes in the presence of surface active agents. - J. Colloid Interface Sci., 1972 , v. 40 , N 3, p. 317-328.

5. S a t a, T. Modification of properties of ion exchange membranes. III. Interaction between ion exchange membranes and surface active agents. - J. Colloid and Polymer Sci., 1978, v. 256, N 1, p. 62-77.

6. Гнусин Н. П., Гребенюк В. Д. Электрохимия гранулированных ионитов. Киев, 1972 , с. $110-116$.

7. Салдадзе К. М., Пашков А. В., Титов В. С. Ионообменные высокомолекулярные соединения. М., 1960.

8. Subraman a a n, V., L a kshmin a r a n a i a h, N. A. A rapid method oi determination of electrical conductance of ion-exchange membranes. - J. Phys. Chem., 1968, v. 72 , N 12, p. 4314.

9. Гн усин Н. П., Г ребен юк В. Д., Певницкая М. В. Электрохимия ионитов. Новосибирск, 1972 , с. $51-53$.

10. Неволин Ф. В. Химия и технология синтетических моющих средств. М., 1971, c. 103.

11. Гнусин Н. П., Певницкая $М$. В. Поляризационные явления при прохождении электрического тока через нонообменные мембраны. - В кн.: Сннтез и свойства ионообменных материалов. М., 1968, с. $271-277$.

Кубанский государственный университет

Ннститут химии

Академии наук Эстонской ССР
Поступила в редакцию 27/VI 1980 
N. GNUSSIN, N. BEREZINA, RUtt TOMSON,

G. STEPANOVA, Natalja KONONENKO

\section{ANIONIIDSETE MEMBRAANIDE ELEKTROKEEMILINE KAITUMINE PINDAKTIIVSETE ORGAANILISTE AINETE LAHUSTES}

Artikkel käsitleb mõningate anioonaktiivsete pindaktiivsete ainete (detsüül- ja dodetsüülsulfaadi naatriumisoolad, sulfoetaanhappe dodetsüülestri naatriumisool ja n-1-oktüülbenseensulfohappe naatriumisool) ning erineva tihedusega membraanide (heteropoorne tööstuslik membraan MA-41, isopoorne membraan MA-41И ja makropoorne membraan MA-41П) vastastikust toimet. On näidatud, et membraanide elektrokeemilised omadused sôltuvad pindaktiivse ühendi struktuurist, nimelt suurendab keerukama ehitusega pindaktiivne aine membraani selektiivsust teatud iooni suhtes.

N. GNUSIN, N. BEREZINA, RUtt TOMSON,

G. STEPANOVA, Natalya KONONENKO

\section{ELECTROCHEMICAL BEHAVIOUR OF ANION EXCHANGE MEMBRANES IN SOLUTIONS OF ORGANIC SURFACE-ACTIVE AGENTS}

The article deals with the interaction of surfactants (sodium decyl- and dodecylsulphates, dodecyl ether of sodium sulphoacetate and sodium-1-octyl benzenesulphonate) and anion exchange membranes of various porosity (industrial heteroporous membrane MA-41, iso-

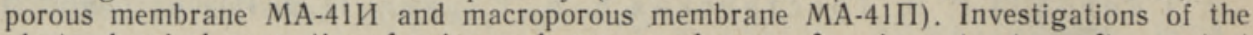
electrochemical properties of anion exchange membranes of various structure after contact with water solutions of surfactants have indicated that the more complicated structures of surfactants lead to a greater selectivity of membranes in relation to the given ion, revealing a considerable decrease of conductivity within the limits of the current of polarization curves. 